\title{
Early Treatment of Class II Division 1 Malocclusion by Modified Teuscher Activator with Lip Bumper: A Case Series
}

\author{
Mohammed Al-Awdi, Ahmad Hafez, Maher Fouda \\ Department of Orthodontics, Faculty of Dentistry, Mansoura University, Mansoura - 35516, Egypt
}

Email for correspondence: altabeeb2006@yahoo.com

\begin{abstract}
Context: Class II malocclusion is considered as one of the most prevalent types of malocclusion encountered in routine orthodontic practice and described by an improper relationship among the upper and lower jaws caused by dental or skeletal problems or a combination of both. Aims and Objective: To evaluate the effects of early treatment of Class II Division 1 malocclusion by modified Teuscher activator with lip bumper. Materials and Methods: The current prospective clinical study consisted of 15 subjects ( 8 girls and 7 boys) with skeletal Class II Division 1 malocclusion due to retrognathism of the mandible with the mean chronological age of $(10.4 \pm 0.6$ years $)$. Lateral cephalograms were taken before (0) and after (1) treatment. Results: Treatment of growing patients with modified Teuscher activator led to correction of Class II Division 1 malocclusion by advancement of mandible (SNB; 2.61 ), increase of mandibular length (Co-Gn; $3.58 \mathrm{~mm}$ ), restriction of maxillary growth (SNA; 0.13 ), and decrease of overjet $(5.45 \mathrm{~mm})$. Conclusion: Modified Teuscher activator was an effective appliance in managing growing patients with Class II Division 1 due to mandibular retrusion.
\end{abstract}

Key words: Class II Division 1 malocclusion, growing patients, lip bumper, modified Teuscher activator

\section{INTRODUCTION}

Class II malocclusion is considered as one of the most prevalent types of malocclusion encountered in routine orthodontic practice and described by an improper relationship among the upper and lower jaws caused by dental or skeletal problems or a combination of both. ${ }^{[1]}$ According to McNamara, Class II malocclusions result mostly from a relative mandibular retrognathism rather than from a maxillary prognathism. There are several important benefits which have been referred to the early management of Class II malocclusion such as prevention of the development of dysfunction,

\begin{tabular}{|l|l|}
\hline Quick Response Code & Article Info: \\
\hline doi: 10.5866/2017.9.10144 \\
\hline $\begin{array}{l}\text { Received: } 11-08-2017 \\
\text { Revised: 15-09-2017 } \\
\text { Accepted: 22-09-2017 } \\
\text { Available Online: 27-11-2017 (www.nacd. } \\
\text { in)(C NAD, 2017 - All rights reserved }\end{array}$ \\
\hline
\end{tabular}

avoidance of upper incisors trauma as a result of large overjet, esthetic improvement, psychosocial advantages for the child during an important formative period of life, and better prediction for the adolescent phase of treatment. ${ }^{[2]}$ As a consequence, the treatment of choice for Class II malocclusion frequently requires mandibular advancement rather than maxillary retraction. In this respect, and in a historical sense, functional appliances of different designs have frequently been used in attempts to enhance mandibular growth. ${ }^{[3]}$ Management of Class II malocclusion using functional appliances has become popular since the introduction of activator by Andersen. Teuscher activator is a variety of functional orthopedic appliance. Their actions depended on holding the mandible in advanced position and create muscle stretching. To inhibit the forward growth of maxilla, stimulate condylar growth and improvement of the muscle pattern. ${ }^{[4]}$

The present study was carried out to evaluate the effects of early treatment of Class II Division 
1 malocclusion by modified Teuscher activator with lip bumper.

\section{MATERIALS AND METHODS}

The present study was conducted from the Orthodontic Department, Faculty of Dentistry. The study involved 15 patients ( 7 boys and 8 girls) with skeletal Class II Division 1 malocclusion due to mandibular retrognathism with a mean age of (10.4 \pm 0.6 years). The patients were selected to manage with modified Teuscher activator with lip bumper [Figure 1] and were followed for (13.6 \pm 2.1 months). Parents of all subjects were provided informed consents.

The criteria for treatment were as follows:

- Skeletal Class II Division 1 malocclusion.

- Dental Class II Division 1 malocclusion.

- Overjet (>6 mm).

- Crowded lower anterior teeth.

Exclusion criteria were as follows:

- Abnormal oral habits.

- High mandibular plane angle

- Previous orthodontic treatment or orthognathic surgery.

- Systemic disease that may influence orthodontic treatment.

The activator appliance was fabricated according to the original design of Teuscher, with modification in the capping of the mandibular front teeth. In addition to the lip bumper inserted into the headgear tube placed between the maxillary and mandibular teeth in the premolars area. Constriction bite was obtained by the aid of exactobite with $4-5 \mathrm{~mm}$ symmetrical advancement of the mandible every

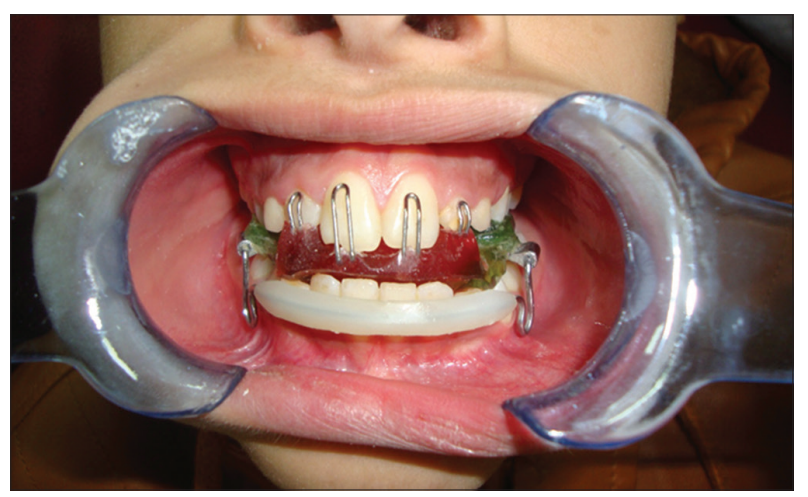

Figure 1: Teuscher activator with lip bumper single step and 2-3 $\mathrm{mm}$ bite opening in the molars region. After insertion and fitting of the appliance, at every visit, the fit of the appliance was checked and the progress of the treatment was assessed by measuring the overjet. Patients were informed to wear the appliance $14 \mathrm{~h} /$ day. Trimming on the occlusal aspect was performed to encourage the eruption of teeth. When the treatment goals had been met and stability seem secured, patients were informed to wear the activator at night as a retainer and gradual reduction in the wearing hours was done.

Lateral cephalometric radiographs were obtained before (T0) and after (T1) treatment. All patients were informed to bite until the maximum intercuspation was achieved and their lips in a relaxed position during the capture.

The reference points and lines used are shown in Figure 2. Skeletal and dental measurements were showed in Figures 3-5 and Table 1.

\section{Method error}

For intraobserver reliability, all cephalograms of the present study were manually traced and measured by one investigator. After 8 days, all measurements were repeated and the mean value of both measurements was utilized. The intraclass correlation coefficient showed excellent intraobserver reliability test (Table 2).

\section{Statistical analysis}

The statistical analysis was achieved using SPSS software version 21.0 (SPSS, Chicago, IL., USA). Data were explored for normality using a Shapiro-Wilk test that shows it was normally distributed. A descriptive statistical analysis was used to present the data as the mean and standard deviation (SD). Paired sample $t$-test was used to evaluate the significance of the difference in the pre- and post-treatment data.

\section{RESULTS}

All included cases had a Class II Division 1 malocclusion and increased overjet more than $6 \mathrm{~mm}$. The duration of management was (13.6 \pm 2.1 months). Mean and SD values for every pre-treatment and post-treatment of skeletal and dental variables were calculated as shown in Table 3.

\section{Sagittal analysis}

The cephalometric measurements of pre- and post-treatment are showed favorable treatment results on the sagittal plane. All variables 


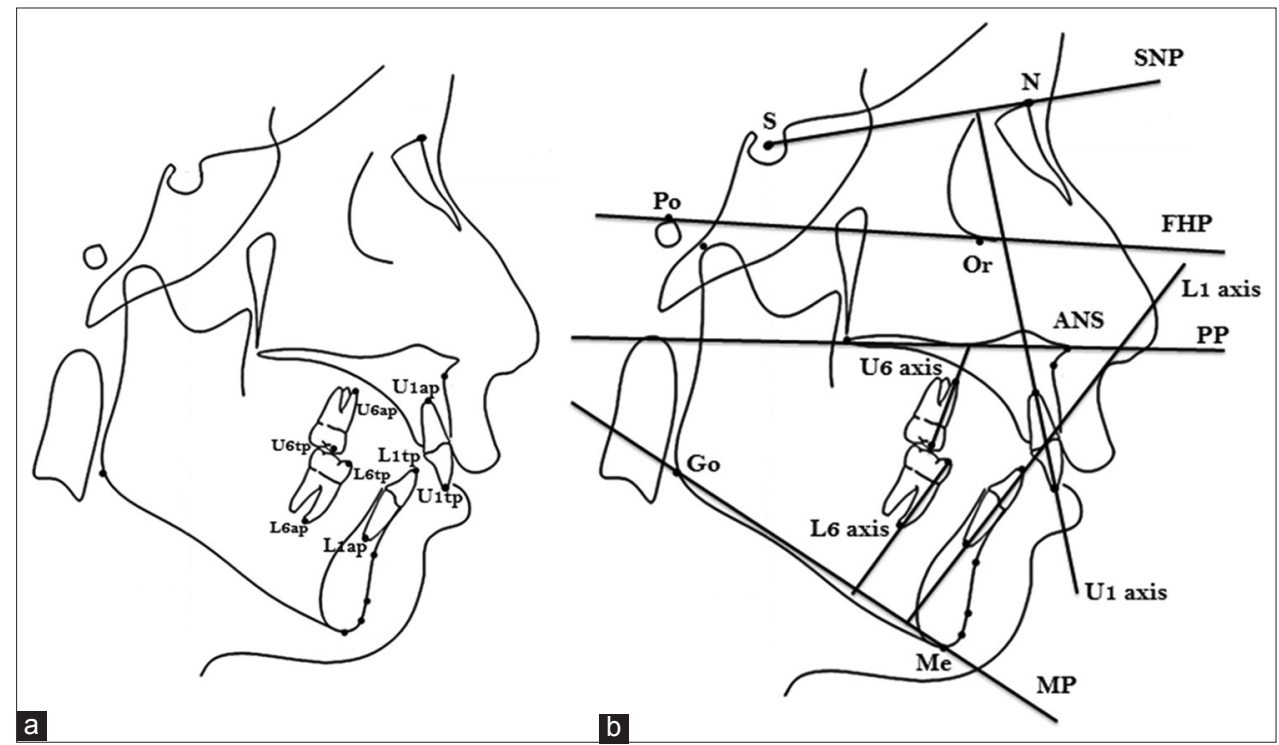

Figure 2: (a) Dental reference points: Upper central incisor apex (U1ap), upper central incisor incisal tip (U1tp), upper first molar mesial root apex (U6ap), upper first molar mesial cusp tip (U6tp), lower central incisor incisal tip (L1tp), lower central incisor apex (L1ap), lower first molar mesial cusp tip (L6tp), and lower first molar mesial root apex (L6ap). (b) Lateral cephalometric radiographs skeletal reference points: Nasion (N), sella (S), orbitale (Or), porion (Po), condylon(Co), anterior nasal spine (ANS), posterior nasal spine (PNS), point (A), point (B), gnathion (Gn), menton (Me), and gonion (Go). Reference lines C: SN plane (SNP), Frankfort horizontal plane (FHP), palatal plane (PP), mandibular plane (MP), occlusal plane (OL), upper central incisor long axis line (U1axis), upper first molar long axis line (U6 axis), lower central incisor long axis line (L1 axis), and lower first molar long axis line (L6 axis)

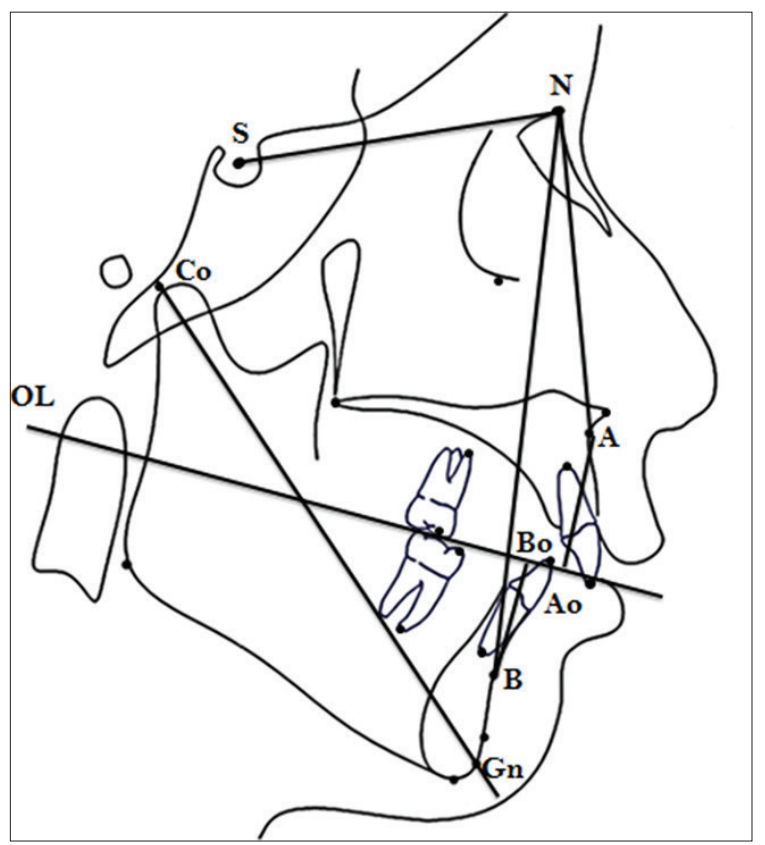

Figure 3: Sagittal skeletal measurements: $\mathrm{SNA}^{\circ}, \mathrm{SNB}^{\circ}, \mathrm{ANB}^{\circ}$, $\mathrm{AO}-\mathrm{BO}(\mathrm{mm})$, and $\mathrm{Co}-\mathrm{Gn}(\mathrm{mm})$

revealed significant changes except SNA $(0.13 \pm$ 0.22 ). Improvement in the patients profile was confirmed by a significant increase of both SNB

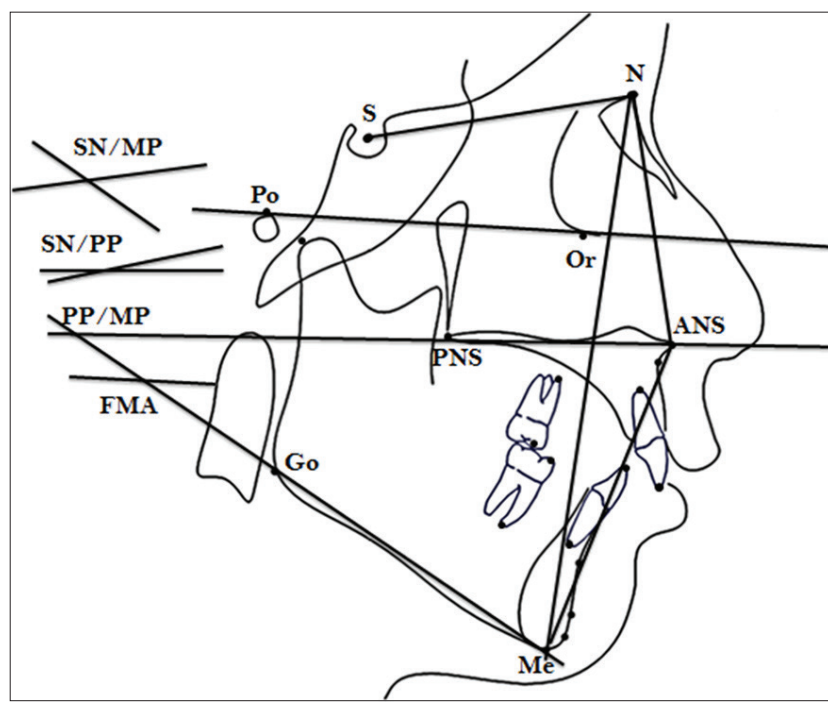

Figure 4: Vertical skeletal measurements: $\mathrm{FMA}^{\circ}, \mathrm{PP} / \mathrm{MP}^{\circ}$, $\mathrm{SN} / \mathrm{MP}^{\circ}, \mathrm{SN} / \mathrm{PP}^{\circ}, \mathrm{N}-\mathrm{Me}(\mathrm{mm}), \mathrm{N}-\mathrm{ANS}(\mathrm{mm})$, and ANS-Me $(\mathrm{mm})$

$(2.16 \pm 0.61)$ and $\mathrm{ANB}^{\circ}(2.73 \pm 1.36)$. Linear measurements in the sagittal plane revealed a significant increase. The mandibular length $(\mathrm{Co}-$ Gn ) increased by $3.58 \pm 1.61 \mathrm{~mm}$. Both overjet and $\mathrm{AO}-\mathrm{BO} \mathrm{mm}$ were significantly decreased by $5.45 \pm 0.69 \mathrm{~mm}$ and $2.79 \pm 1.22 \mathrm{~mm}$, respectively. 


\begin{tabular}{|c|c|c|c|c|c|c|c|c|}
\hline \multirow[t]{2}{*}{ Variable } & \multicolumn{2}{|c|}{ Before } & \multicolumn{2}{|c|}{ After } & \multirow[t]{2}{*}{ Mean } & \multirow[t]{2}{*}{ SD } & \multirow[t]{2}{*}{$P$ value } & \multirow[t]{2}{*}{ Sig. } \\
\hline & Mean & SD & Mean & SD & & & & \\
\hline $\mathrm{SNA}^{\circ}$ & 80.02 & 0.93 & 79.89 & 0.80 & 0.13 & 0.22 & 0.103 & $*$ \\
\hline $\mathrm{SNB}^{\circ}$ & 73.65 & 0.96 & 75.81 & 0.92 & -2.16 & 0.61 & $0.000 * * *$ & $* * *$ \\
\hline $\mathrm{ANB}^{\circ}$ & 6.07 & 1.70 & 3.34 & 0.88 & 2.73 & 1.36 & $0.000 * * *$ & $* * *$ \\
\hline FMA $^{\circ}$ & 26.48 & 3.04 & 27.55 & 4.61 & -1.07 & 2.75 & 0.250 & NS \\
\hline $\mathrm{SN} / \mathrm{PP}^{\circ}$ & 8.79 & 1.82 & 8.81 & 1.77 & -0.02 & 0.79 & 0.938 & NS \\
\hline $\mathrm{PP} / \mathrm{MP}^{\circ}$ & 29.91 & 3.48 & 30.17 & 3.00 & -0.26 & 0.69 & 0.266 & NS \\
\hline $\mathrm{SN} / \mathrm{MP}^{\circ}$ & 36.70 & 4.47 & 37.09 & 5.50 & -0.39 & 0.73 & 0.129 & NS \\
\hline $\mathrm{N}-\mathrm{Me}(\mathrm{mm})$ & 104.32 & 3.09 & 106.88 & 3.58 & -2.56 & 0.98 & 0.000 & $* * *$ \\
\hline N-ANS (mm) & 45.78 & 3.21 & 46.48 & 3.22 & -0.70 & 0.83 & 0.026 & $*$ \\
\hline ANS-Me (mm) & 58.33 & 2.69 & 60.81 & 3.18 & -2.48 & 1.10 & 0.000 & $* * *$ \\
\hline Co-Gn (mm) & 96.00 & 3.40 & 99.59 & 4.33 & -3.58 & 1.61 & 0.000 & $* * *$ \\
\hline $\mathrm{U} 1 / \mathrm{SN}^{\circ}$ & 104.65 & 4.13 & 102.71 & 4.49 & 1.94 & 2.01 & 0.014 & $* *$ \\
\hline $\mathrm{U} 1 / \mathrm{L} 1^{\circ}$ & 123.47 & 3.55 & 124.95 & 4.07 & -1.57 & 0.399 & 0.003 & $* *$ \\
\hline $\mathrm{L} 1 / \mathrm{MP}^{\circ}$ & 92.14 & 5.61 & 95.67 & 4.85 & -33.53 & 2.48 & 0.002 & $* *$ \\
\hline $\mathrm{L} 6 / \mathrm{MP}^{\circ}$ & 83.71 & 3.50 & 82.48 & 3.71 & 1.23 & 1.64 & 0.043 & $*$ \\
\hline L1-Me (mm) & 36.81 & 2.20 & 37.85 & 2.68 & -1.04 & 0.87 & 0.004 & $* *$ \\
\hline $\mathrm{AO}-\mathrm{BO}(\mathrm{mm})$ & 3.89 & 0.92 & 1.10 & 0.92 & 2.79 & 1.22 & 0.000 & $* * *$ \\
\hline Overjet (mm) & 8.14 & 0.48 & 2.69 & 0.41 & 5.45 & 0.69 & 0.000 & $* * *$ \\
\hline Overbite (mm) & 4.46 & 1.35 & 3.21 & 0.88 & 1.24 & 0.96 & 0.003 & $* *$ \\
\hline
\end{tabular}

$P<0.05$, NS: Not significant. ${ }^{*} P<0.05, * * P<0.01$, *** $P<0.0001$

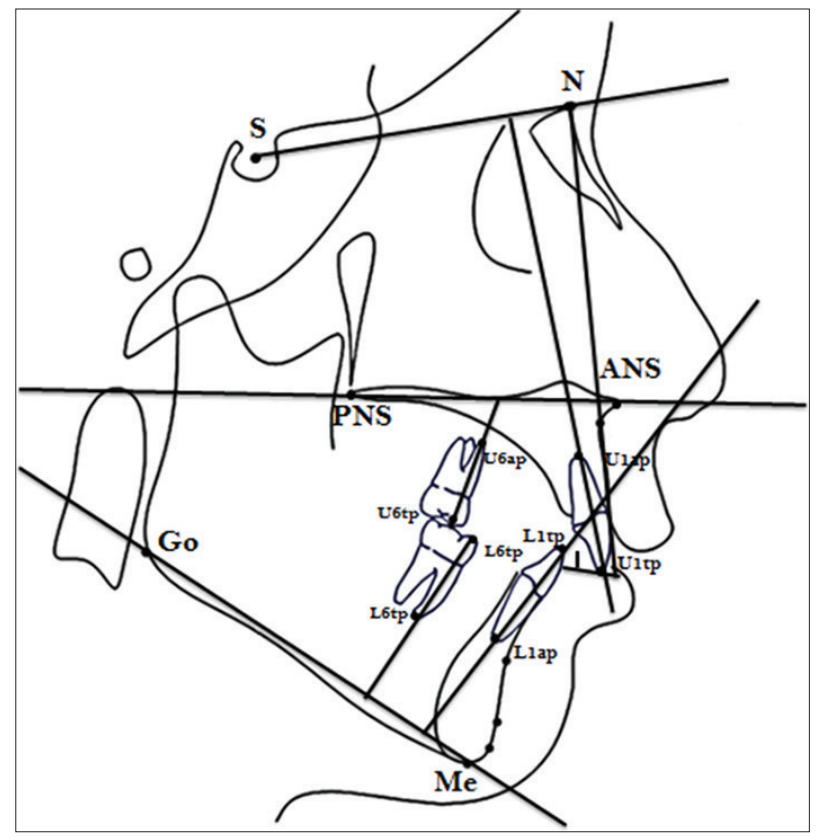

Figure 5: Dental measurements: U1/SN , U1/L1, L1/MP, L6/MP , L1-MP (mm), overjet (mm), and overbite (mm)

Furthermore, the overbite showed significant decrease by $(1.24 \pm 0.96 \mathrm{~mm})$.

\section{Vertical analysis}

The angular measurements in the vertical plane (FMA : $1.07 \pm 2.75)$, (SN-PP : $0.020 \pm 0.79)$, (SNMP : $0.39 \pm 0.73)$, and (PP-MP : $0.26 \pm 0.69)$ were showed a nonsignificant increase. On the other hand, total anterior, upper anterior, and lower anterior facial heights measurements revealed significant increase (N-Me: $2.56 \pm 0.98 \mathrm{~mm}),(\mathrm{N}-\mathrm{ANS}: 0.70 \pm$ $0.83 \mathrm{~mm}$ ), and (ANS-Me: $2.48 \pm 1.10 \mathrm{~mm}$ ).

\section{Dentoalveolar analysis}

The linear and angular dentoalveolar measurements showed significant changes except the upper posterior dentoalveolar height (U6-PP mm). Modified activator management moved the upper incisor palatally (U1-SN : $1.94 \pm 2.01$ ) with an increase in the interincisal angle (U1-L1 : $1.57 \pm 0.399$ ) and led to extrusion of these teeth (U1-PP: $0.42 \pm 0.35 \mathrm{~mm}$ ). On the other hand, lower incisors extruded (L1-Me: $1.04 \pm$ $0.87 \mathrm{~mm}$ ) and moved labially (L1-MP : $1.29 \pm 1.07$ ). Furthermore, the lower first permanent extruded (L6-MP: $1.64 \pm 1.22 \mathrm{~mm}$ ) and tipped mesially (L6MP : $1.23 \pm 1.64)$. Highly significant reduction of overjet $(5.45 \pm 0.69 \mathrm{~mm}),(\mathrm{AO}-\mathrm{BO}: 2.79 \pm 1.22 \mathrm{~mm})$, 


\begin{tabular}{|c|c|}
\hline Landmark & Definition \\
\hline \multicolumn{2}{|c|}{ Skeletal measurements } \\
\hline \multicolumn{2}{|c|}{ SNA Angle formed between Sella, nasion and point A } \\
\hline SNB & Angle formed between Sella, nasion and point B \\
\hline ANB & Angle formed between point A, nasion and point B \\
\hline FMA & Frankfort's mandibular plane angle. \\
\hline $\mathrm{SN} / \mathrm{PP}$ & Angle formed between Sella-nasion and palatal plane. \\
\hline $\mathrm{PP} / \mathrm{MP}$ & Angle formed between Palatal plane and mandibular plane. \\
\hline $\mathrm{SN} / \mathrm{MP}$ & Angle formed between Sella-nasion and mandibular plane. \\
\hline $\mathrm{N}-\mathrm{Me}(\mathrm{mm})$ & Total face height \\
\hline N-ANS (mm) & Upper anterior face height \\
\hline ANS-Me (mm) & Lower anterior face height \\
\hline Co-Gn (mm) & Mandibular length \\
\hline \multicolumn{2}{|c|}{ Dento-alveolar measurements } \\
\hline U1/SN & Angle formed between Upper incisor axis and sella-nasion \\
\hline $\mathrm{U} 1 / \mathrm{L} 1$ & Interincisal angle \\
\hline L6/MP & Lower first permanent molar crown angulations to mandibular plane \\
\hline L1/MP & angle formed between Lower incisor and mandibular plane \\
\hline L1-MP (mm) & The distance between the lower incisor cusp tip and the mandibular plane \\
\hline $\mathrm{AO}-\mathrm{BO}(\mathrm{mm})$ & The points of contact on the occlusal plane from points A and B \\
\hline Overjet (mm) & Horizontal distance between upper most protruded incisor and lower incisal edges \\
\hline Overbite (mm) & The vertical overlap of mandibular incisors by the maxillary incisors during occlusion \\
\hline
\end{tabular}

and overbite $(1.24 \pm 0.96 \mathrm{~mm})$. Figures 6 and 7 illustrate the pre- and post-treatment of intra- and extra-oral changes.

\section{DISCUSSION}

The activator functional appliance obviously produces dental and skeletal changes on growing subjects with Class II Division 1 relationship. These changes are not equally distributed throughout the craniofacial complex. The aim of current study was to evaluate the skeletal and dentoalveolar changes on cases with Class II Division 1 relationship due to mandibular retrognathism treated by modified Teuscher activator with lip bumper.

\section{Maxillary effects}

The treatment with modified Teuscher activator showed inhibition of the maxillary growth. That may due to the forward advancement of the mandible by the activator which might be produced retrusive force to the maxilla. In addition, the lip bumper force exerted by labial muscles. This may illustrate by nonsignificant decrease of SNA $(0.13 \pm 0.22)$. This result was in harmony with previous studies. ${ }^{[2,5,6]}$ However, it was not in line with the results of Dalci et al. ${ }^{[7]}$

\section{Mandibular effects}

The most evident changes of the modified activator were on the mandible. Forward advancement of mandibular landmarks and increase in the mandibular length showed highly significant increase in (SNB) and (Co-Go mm), respectively. These outcomes could be explained by the mandibular adaption to the new advanced position. Several studies were similar to the findings in this study. ${ }^{[8,9]}$ On the other hand, these results were disagreed with Lux et al. ${ }^{[10]}$ and Janson et al. ${ }^{[4]}$

\section{Effects on the vertical dimension}

In this study, the management with modified activator seems to increase the facial height. The linear measurements (N-Me), (N-ANS), and (ANS-Me) showed significant increase, while the angular measurements (FMA ), (SN-PP ), (SN-MP ), and (PP-MP ) revealed nonsignificant changes. This may due to backward rotation of the mandible. 


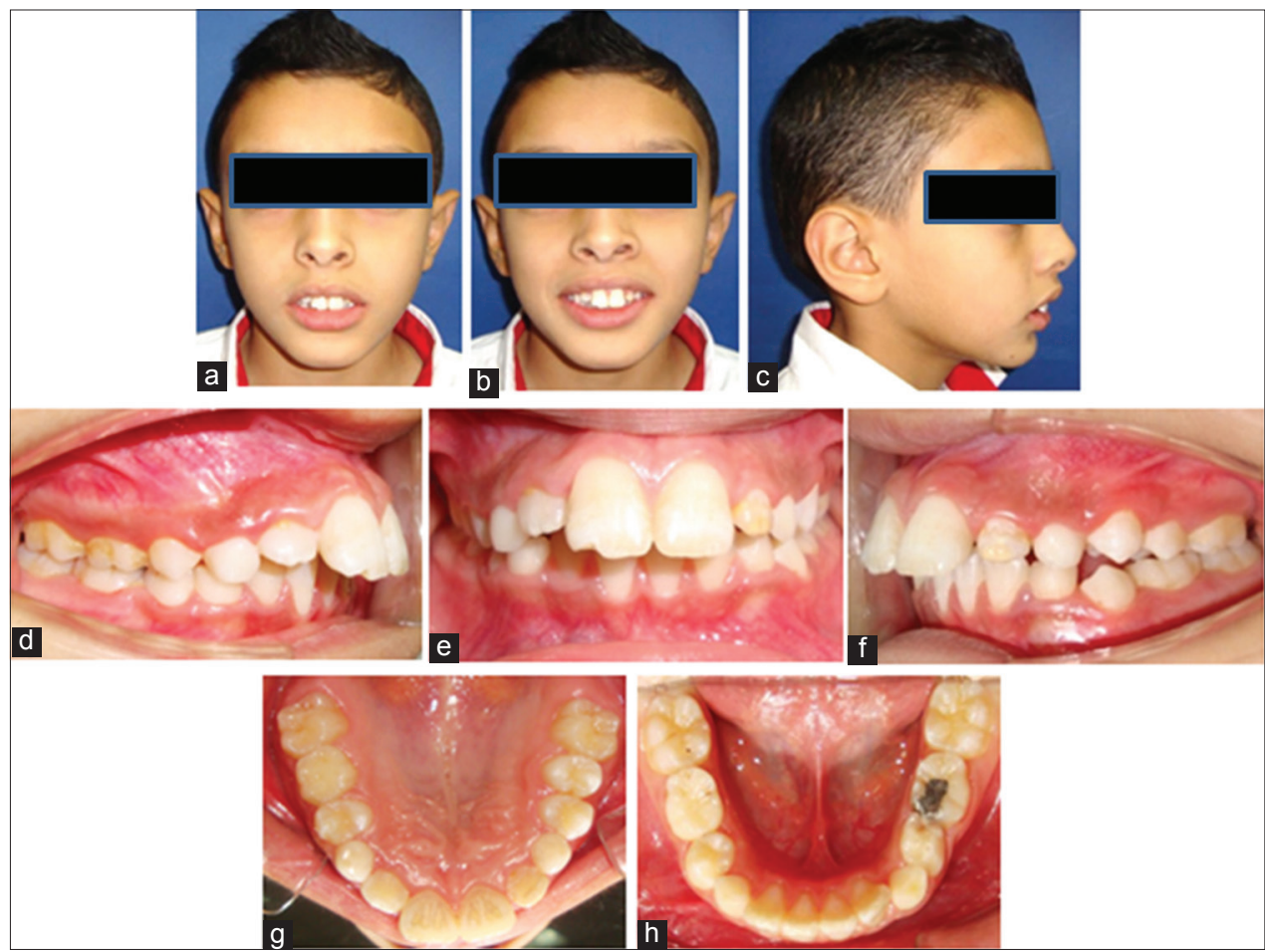

Figure 6: (a-h) Pre-treatment photographs showing Class II Division 1 malocclusion

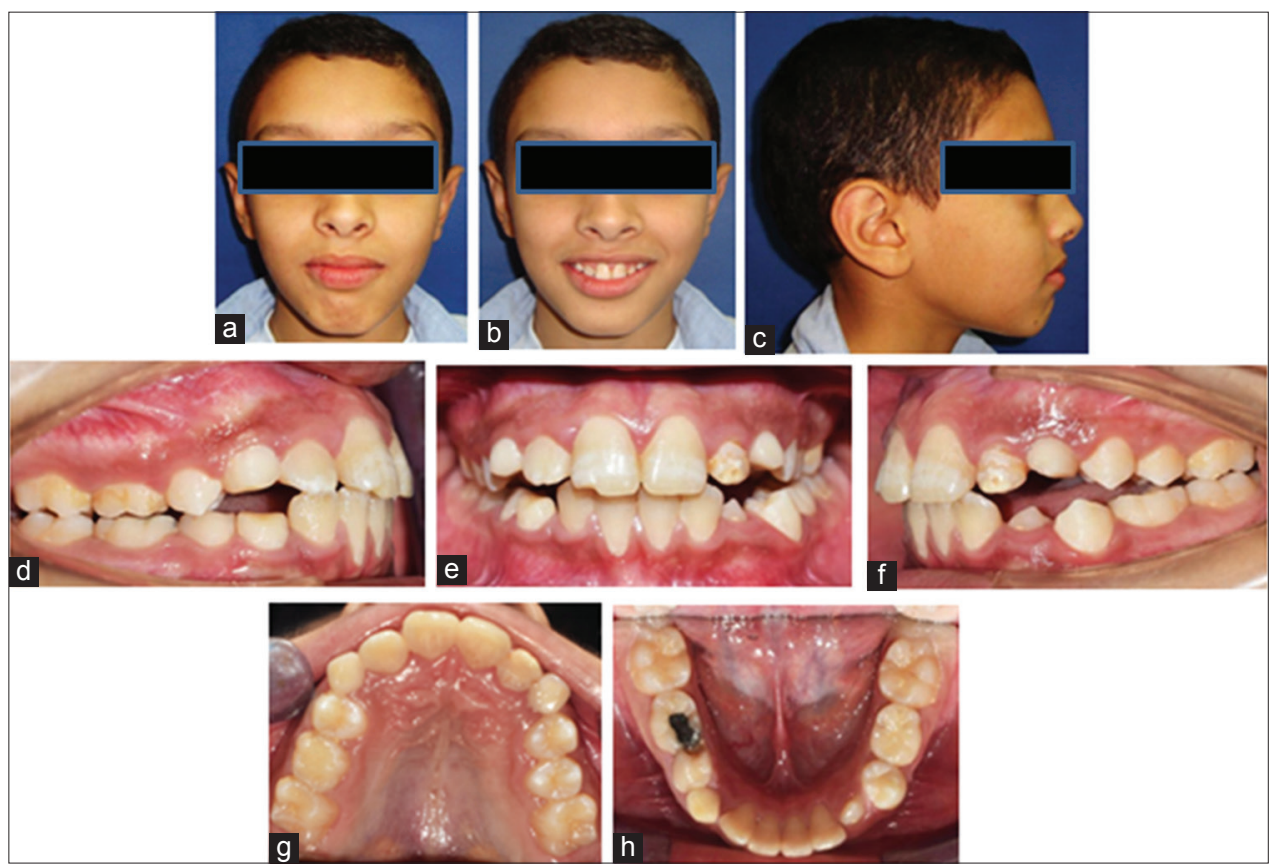

Figure 7: (a-h) Post-treatment photographs showing correction of Class II Division 1 malocclusion

Therefore, it is imperative to avoid high angle cases to be treated with modified activator. These findings were in line with other studies. ${ }^{[11-13]}$

\section{Dentoalveolar effects}

In the present study, the maxillary incisors showed pronounced extrusion, palatal movement, 


\begin{tabular}{ll} 
Table 3: Intra-class correlation coefficient (ICC) & \\
Variables & ICC \\
\hline SNA & 0.85 \\
SNB & 0.88 \\
ANB & 0.81 \\
FMA & 0.85 \\
SN/PP & 0.89 \\
PP/MP & 0.82 \\
SN/MP & 0.92 \\
N-Me (mm) & 0.98 \\
N-ANS (mm) & 0.98 \\
ANS-Me $(\mathrm{mm})$ & 0.91 \\
Co-Gn $(\mathrm{mm})$ & 0.97 \\
U1/SN & 0.87 \\
U1/L1 & 0.92 \\
L6/MP & 0.94 \\
L1/MP & 0.87 \\
L1-MP (mm) & 0.82 \\
AO-BO (mm) & 0.95 \\
Overjet (mm) & 0.86 \\
Overbite (mm) & 0.89 \\
\hline
\end{tabular}

and alter in their axial inclination, in spite of these teeth being notched in the acrylic. The relation of upper incisors to the cranial base (U1-SN) and (U1-NA) reduced significantly which in turn indicates palatal tipping of these teeth. Furthermore, the distance from the incisal edges to the palatal plane (U1-PP) was increase significantly. These results were supported by previous studies. ${ }^{[2,13-15]}$

On the other hand, the axial inclination of lower incisors to the mandibular plane (L1-MP) and the distance of the mandibular incisors (L1-MP) presented significant increase to the mandibular plane. This change in the lower incisors might be due to the use of lip bumper with Teuscher activator combined that might break the muscular equilibrium zone and enhanced the proclination of lower incisors. This results were in agreement with other previous studies. ${ }^{[11,16,17]}$

Regarding the lower permanent first molar, the treatment with modified Teuscher activator produced significant changes in the position of these teeth in relation to the mandibular plane. The significant increase in the angle (L6-MP ) indicated mesial drift of these teeth. This might be due to the forward mandibular advancement. Furthermore, the significant increase in the distance (L6-MP) indicated extrusion of the lower first permanent teeth. These findings were similar to other studies. $^{[8,18,19]}$

\section{CONCLUSIONS}

1. The modified Teuscher activator is an effective appliance in the treatment of growing patient with Class II Division 1 relationship due to mandibular retrusion

2. The modified Teuscher activator has skeletal effects in the sagittal plane by retardation of the maxilla, stimulates the forward growth of the mandible and

3. The overjet was reduced due to increase the forward growth of the mandible, palatal tipping of upper incisors, and flaring of lower incisors

4. The improvement in facial profile appearance follows the alteration in the underlying hard tissue structures

5. Further studies are required to assess the longterm stability of the observed changes on hard and soft tissues.

\section{REFERENCES}

1. Proffit WR, Fields HW Jr. Prevalence of malocclusion and orthodontic treatment need in the united states. Int J Adult Orthodon Orthognath Surg 1998;13:97-106.

2. Basciftci FA, Uysal T, Büyükerkmen A, Sari Z. The effects of activator treatment on the craniofacial structures of Class II division 1 patients. Eur J Orthod 2003;25:87-93.

3. McNamara JA Jr. Components of Class II malocclusion in children 8-10 years of age. Angle Orthod 1981;51:177-202.

4. Janson G, Caffer Dde C, Henriques JF, de Freitas MR, Neves LS. Stability of Class II, division 1 treatment with the headgear-activator combination followed by the edgewise appliance. Angle Orthod 2004;74:594-604.

5. Cozza P, De Toffol L, Colagrossi S. Dentoskeletal effects and facial profile changes during activator therapy. Eur J Orthod 2004;26:293-302.

6. Lerstøl M, Torget O, Vandevska-Radunovic V. Longterm stability of dentoalveolar and skeletal changes after activator-headgear treatment. Eur J Orthod 2010;32:28-35.

7. Dalci O, Altug AT, Memikoglu UT. Treatment effects of a twin-force bite corrector versus an activator in comparison with an untreated Class II sample: A preliminary report. Aust Orthod J 2014;30:45-53.

8. Singh GD, Thind BS. Effects of the headgear-activator teuscher appliance in the treatment of Class II Division 1 malocclusion: A geometric morphometric study. Orthod Craniofac Res 2003;6:88-95.

9. Marsan G. Effects of activator and high-pull headgear combination therapy: Skeletal, dentoalveolar, and soft 
tissue profile changes. Eur J Orthod 2007;29:140-8.

10. Lux CJ, Rübel J, Starke J, Conradt C, Stellzig PA, Komposch PG. Effects of early activator treatment in patients with Class II malocclusion evaluated by thin-plate spline analysis. Angle Orthod 2001;71:120-6.

11. Türkkahraman H, Sayin MO. Effects of activator and activator headgear treatment: Comparison with untreated Class II subjects. Eur J Orthod 2006;28:27-34.

12. Ruf S, Baltromejus S, Pancherz H. Effective condylar growth and chin position changes in activator treatment: A cephalometric roentgenographic study. Angle Orthod 2001;71:4-11.

13. Weiland FJ, Ingervall B, Bantleon HP, Droacht H. Initial effects of treatment of Class II malocclusion with the herren activator, activator-headgear combination, and Jasper Jumper. Am J Orthod Dentofacial Orthop 1997;112:19-27.

14. Levin RI. Activator headgear therapy. Am J Orthod 1985;87:91-109.
15. Altenburger E, Ingervall $\mathrm{B}$. The initial effects of the treatment of Class II, Division 1 malocclusions with the van beek activator compared with the effects of the herren activator and an activator-headgear combination. Eur $\mathrm{J}$ Orthod 1998;20:389-97.

16. Bendeus M, Hägg U, Rabie B. Growth and treatment changes in patients treated with a headgear-activator appliance. Am J Orthod Dentofacial Orthop 2002;121:376-84.

17. O'Donnell S, Nanda RS, Ghosh J. Perioral forces and dental changes resulting from mandibular lip bumper treatment. Am J Orthod Dentofacial Orthop 1998;113:247-55.

18. Uçüncü N, Türk T, Carels C. Comparison of modified teuscher and van beek functional appliance therapies in high-angle cases. J Orofac Orthop 2001;62:224-37.

19. Lagerström LO, Nielsen IL, Lee R, Isaacson RJ. Dental and skeletal contributions to occlusal correction in patients treated with the high-pull headgear-activator combination. Am J Orthod Dentofacial Orthop 1990;97:495-504. 